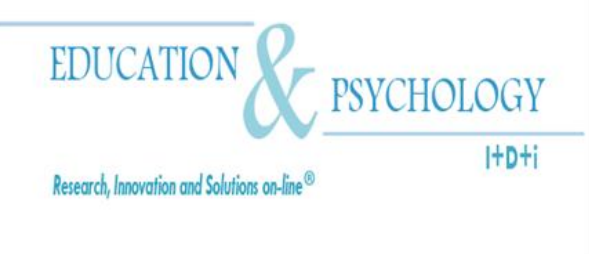

\title{
Optimism and Pessimism of Physical Education and Non-Physical Education Students: Invariance of Structure ${ }^{1}$
}

\author{
Maher M. Abu-Hilal ${ }^{1}$, Kashef Zayed $^{2}$ \\ ${ }^{1}$ Department of Psychology, Sultan Qaboos University, Muscat \\ ${ }^{2}$ Department of Physical Education, Sultan Qaboos University, Muscat
}

\section{Oman}

Correspondence: Maher M. Abu Hilal, P.O. Box 32, Dept. of Psychology, SQU, Muscat, PC123. Oman. Email: mhilal@squ.edu.om

(C) Education \& Psychology I+D+i and Editorial EOS (Spain)

\footnotetext{
${ }^{1}$ An earlier version of this paper was presented at the American Psychological Association's Annual Conference, July, 2010, San Diego, CA, USA.
} 


\section{Abstract}

Introduction. Optimisim and pessimism are two psychological constructs that play a significant role in human mental and psychological hygiene. The two construct are strongly but negatively correlated. Optimisim and pessimisim can be influenced by culture and the environment. The present study attempts to test the structure of optimisim and pessimisim across two countries: United Arab Emirates and Oman. Also, physical education students were compared to non-physical education students.

Method. College students from SQU in Oman $(n=103)$ and the UAEU $(n=200)$ participated in the study. The sample was a convenient one. The SQU sample was primarily physical education students (males $=60$, females $=43$ ). The instrument consisted of thirty Likerttype items. Optimism was measured by 15 items and so as pessimism.

Results. Exploratory factor analysis clearly identified two factors rather than one bipolar factor. The number of factors (2), the pattern of factor loadings, the factor correlations and uniqueness were invariant across P.E. and non P.E samples. MANOVA revealed that P.E. subjects were more optimistic than non P.E. subjects. However, no significant difference was found in pessimism between P.E. and non P.E. subjects.

Discussion and Conclusion. The results revealed that optimisim and pessimism can influenced by the immediate environment as well as the type of study. It terms of structure, the instrument was as valid and reliable in Oman and UAE as it was valid and reliable in Kuwait where the instrument was originally developed and standardized.

Keywords: optimisim, pessimisim, physical education, Oman, United Arab Emirates, college students.

Received: 06/06/11 Initial acceptance: 07/05/11 Final acceptance: 11/04/11 


\section{Optimismo y pesimismo de alumnos de educación física y otros: invariabilidad de estructura Resumen}

Introducción. Optimismo y pesimismo son dos constructos psicológicos que juegan un papel significativo en la higiene mental humana y psicológica. Estas dos construcciones están fuertemente correlacionadas, pero negativamente. Optimismo y pessimisim puede estar influenciada por la cultura. El presente estudio intenta para poner a prueba la estructura del optimismo y pesimisimo a través de dos países: Emiratos Árabes Unidos y Omán. Además, los estudiantes de educación física fueron comparados con los estudiantes de educación no-física.

Método. Estudiantes universitarios de SQU en Omán $(n=103)$ y el UAEU $(n=200)$ participaron en el estudio. La muestra SQU fue principalmente de estudiantes de educación física (hombres $=60$, mujeres $=43$ ). El instrumento consiste en treinta ítems tipo Likert. El optimismo y el pesimismo se evaluó a través de 15 items, cada uno.

Resultados. El análisis factorial exploratorio identificó claramente dos factores más que un factor bipolar. El número de factores (2), el patrón de cargas de cada factor , las correlaciones de los factores y singularidad eran invariables a través de Educación Física (PE) y las muestras de no P.E (NPE) . El MANOVA reveló que los sujetos educación física se mostraron más optimistas que los que no eran deeducación física. Sin embargo, no se encontraron diferencias significativas en el pesimismo entre los PE educación física y los que eran de educación física.

Discusión y Conclusiones. Los resultados revelaron que optimismo y pesimismo pueden influidas por el entorno inmediato, así como el tipo de estudio. En cuanto a la estructura, el instrumento fue tan válida y fiable en Omán y en los Emiratos Árabes Unidos, ya que era válido y fiable en Kuwait, donde se desarrolló el instrumento original y estandarizado.

Palabras clave: Optimisimo, pesimisimo, educación física, Omán, Emiratos Árabes Unidos, estuantes universitarios. 


\section{Introduction}

Human traits and emotions are generally related and they may affect one another reciprocally. For example, Nicholls, Polman, Levy, and Backhouse (2008) found that optimism and pessimism were significantly correlated with eight coping constructs, (e.g., mental imagery, effort expenditure, thought control). Researchers in some Arab countries as well as through cross-culture studies (western vs. non-western) found that optimism and pessimism were significantly correlated with depression and anxiety (Abdel-Khalek, \& Laster, 2006; Abdel-Khalek, \& Maltby, 2008; Abu Hilal, 2006; Alansari, \& Kazem, 2008; Sheier, Carver, \& Bridges, 1994). According to Carver, Scheierb, and Segerstromc (2010), "the trait of optimism may provide cognitive, coping, and contextual resources that promote better mental health" (p. 880). Also, Abdel-Khalek and Lester (2006) found that optimisim is related to better outcomes (e. g., good physical health, coping, satisfaction with life), but pessimism is related to bad outcomes (e.g., poor physical health).

Like many other human traits and emotions, optimism and pessimism's definition, nature and structure have been subject of profound disagreement (Abdel-Khalek, 2000; AbdelLatif \& Hamadeh, 1998; and Chang, et al, 2008). In other words, researchers disagree on both the substantive front (optimism's content and definition) and the methodological front (optimism's measurement and structure). On the substantive front, Chang, et al. (2008) has indicated that researchers disagree on the definitions of the two constructs and the relation between them. Chang et al (2008) indicated that the most accepted definition of the two constructs was offered by Scheier et al (1978) who defined optimism and pessimism as generalized positive and negative outcome expectancies. Some other researchers define the two constructs as a positive and negative outlook on life (Chang, et al, 2008). Crarver and Smith (2010) stated that "Optimism and pessimism reflect confidence versus doubt, not regarding a specific situation but regarding life in general" (p. 683).

On the methodological front, some researchers have viewed optimism and pessimism as a bipolar one construct while others have argued that optimism and pessimism are two distinct but related constructs (Abdel-Khalek, 2000, Abdel-Latif \& Hamadeh, 1998). This falls within the disagreement of researchers on the structure and the relation between the two constructs. This issue can be partially resolved with the factor analytic approach, namely the structural equation modeling (SEM). Marshall, Wortman, Kusulas, Hervig, and Vickers (1992) found that optimism and pessimism are empirically differentiable, but related, constructs. 
Among the disagreements regarding optimism and pessimism is that some theorists and researchers conceptualize the two constructs as dispositional while others argue that they are situational or contextual.

In this study we argue that if optimism and pessimism are dispositional outlooks or perceptions then people would randomly differ on the basis of just individual differences. However, if a certain group of people (e.g., men) is, for example, more optimistic than another (e.g., women), then one can justifiably, infer that optimism or pessimism is situational. Also, if sports people are more optimistic than non-sports people, it may be inferred that optimism is rather contextual than dispositional (see Sanders and Sander, 2007 for comparison of college students on other traits, academic behvioral confidence) .

In the present study we have three groups of people: physical education (P.E.) male students, P.E female students and non-P.E female students. We assume here that P.E and sports provide an opportunity for individuals to interact and probably discharge their constraints and stress, while individuals who have less chance to practice sports would be more stressed and may be less optimistic. Scheier and Carver (1992) indicated that optimistic athletes are most likely having positive perceptions and expectations on life in general. Gordon (2008) found a positive correlation between optimism and performance among soccer athletes. In the Chinese philosophy, happiness can be obtained either by cheering people up and freeing them from constraints, or through expressing oneself openly and interacting with others (Kracher, 1995). Again, nothing can be better than sports in freeing people from constraints and making them interact.

Sorbom et al, (1981) recommended that the structure of a construct should be tested before any invariance test is made which goes in line with our intent to explore the structure of optimism and pessimism across different groups of people in the Arab culture before testing the equality of structure between the Arab culture and other cultures.

In other psychological constructs (e.g. self-concept) Marsh (1990) and Shavelson, and Stanton (1976) argued that many of the instruments assume multidimensionality but when appropriate techniques are used, very few are able to reflect the dimensions they should measure.

This study is important in that it uses a methodology that can test if optimism and pessimism is a uni-dimensional construct or a multi-dimensional one. Usually the dimensionality 
of a construct is investigated within the factor analytic methodology. Within this methodology exploratory factor analysis (EFA) was used. However, EFA has several limitations and may not be the most appropriate method (Marsh, 1987; Marsh \& Hocevar, 1985). While EFA can produce a specified number of factors, it cannot ensure that the factor structure is the one hypothesized by the researcher. With the development of confirmatory factor analysis (CFA), however, it is possible to test how well a hypothesized model can fit data and test even for invariance of factor structure across different groups or subpopulations (Joreskog, \& Sorbom, 1989; Joreskog \& Sorbom, 1993).

During the past ten years, the CFA approach has been widely used in psychological research (Joreskog \& Sorbom, 1993). However, we are not aware of any study in Arabic that might have employed the CFA technique to test the structure of optimism and pessimism. Several studies in the Arab World have compared different groups in optimism and pessimism (Alansari, \& Kazem, 2008) and some compared groups across cultures (Abdel-Khalek \& Lester, 2006; Abdel-Khalek \& Maltby, 2008). However, they have done the comparison without establishing that the structure is invariant across groups. Prior to comparing groups in optimism and pessimism, the present study intends to establish the structure and test if the structure is invariant across the investigated groups.

\section{Method}

\section{Participants}

The sample for this study consisted of 303 college students from Sultan Qaboos University (SQU) in Oman $(\mathrm{n}=103)$ and the United Arab Emirates University (UAEU) ( $\mathrm{n}=$ 200). The sample was a convenient one. The SQU sample was primarily physical education (referred to as P.E.) students (male $=60$, female $=43$ ). All of the subjects in the UAEU sample were female students who were enrolled in the first author's general education classes over two semesters (2005/2006) and referred to as non-P.E. No data is available about the subjects' average age; however, majority of college students in this part of the world range between 17 and 25 .

Samples background. Both Oman and United Arab Emirates are Arab states in the Gulf Cooperative Council (GCC). The Sultan Qaboos University (Sultanate of Oman) is a public, semi co-education institution in that male and female students are not completely se- 
parated. In many Arabian Gulf states (e.g. Saudi Arabi, UAE), college students in government universities go to different campuses, one for boys and one for girls. However, in Oman boys and girls go to one campus with limited coeducation. P.E. male and female students at SQU don't perform or practice sport activities in the same place but only attend lecture classes together. In comparison, UAEU (United Arab Emirates) male and female students are completely separated whether in clases or stport activities. Males have a male campus and so as females. Furthermore, all of the female students live in single sex dormitories that are completely secluded from society and other bodies of the university.

\section{Instruments}

The instrument consisted of thirty Likert-type items. Optimism was measured by 15 items and so as pessimism. The instrument was developed by Abdel-Khalek (2000) who standardized the instrument on a large sample of Kuwait students. The normalization sample is more or less similar to the samples used in this study. Examples of the items in the optimism scale are "Life looks to me beautiful", "The future carries happy surprises to me". Examples of the pessimism scale are "I feel I am the unluckiest person", "Bad luck accompanies me all the time". Abdel-Khalek (2000) derived Cronbach alphas for each of the two scales from the normative sample. They were 0.93 and 0.94 for optimism and pessimism, respectively. Also, Abdel-Khalek and Lester (2006) tested the convergent and divergent cirterion-related validity and found both optimisim and pessimis to be valid. As a criterion, the Life Orientation Test correlated .78 and -.69 with optimism and pessimism, respectively. Cronbach alphas were computed for the present samples for the two scales and were all above 0.87 . for physical education male students, alphas were 0.87 and 0.92 for optimism and pessimism, respectively. Physical education female students had alpha 0.91 for each of the two scales. Female students from UAEU had alphas 0.95 and 0.94 for optimism and pessimism, respectively.

\section{Statistical Analysis and Model}

Exploratory factor analysis (EFA) was first conducted to explore the structure of the full optimism and pessimism scale. Then, optimism and pessimism structure was determined by confirmatory factor analysis (CFA). CFA was conducted with AMOS 16 to test if the structure is invariant across the three groups. The latter analysis was conducted after the items were parceled. Sixteen indexes were computed by summing two items for an index. Item $15-$ 
in the optimism scale- and item 15 -in the pessimism scale- was multiplied by 2 . The indicators that measured optimism were allowed to load only on the optimism latent factor; while the indicators that measured pessimism were allowed to load only on the pessimism latent factor. The models fit were assessed by multiple criteria. These criteria were the $\chi^{2}$ likelihood ratio statistic, the comparative fit index (CFI), the Tucker-Lewis Index (TLI), and the root mean square error of approximation (RMSEA). After testing the model of invariance for the three groups, MANOVA was conducted to assess and compare the level of optimism and pessimism expressed by each of the three groups. Multiple comparisons with Scheffe test $(\mathrm{p}<$ $0.05)$ was used.

\section{Results}

\section{Exploratory Factor Analysis}

The Scree tests for each of the three groups indicated that at least two factors should be extracted. We imposed the number of factors restriction for each of the three groups. It should be noted, however, that due to small samples at the SQU, the results can't be considered as stable as that for the UAEU sample. Table 1 shows the results of the direct oblimin approach. It can be noticed that most items loaded significantly on the factor they were designed to measure for each of the three groups. Particularly, for the UAEU sample, all items designed to measure optimism had significant loadings but loaded very weakly on pessimism. Also, all items designed to measure pessimism had significant loadings with very small loadings on optimism. Correlations between optimism and pessimism were all significantly negative.

Some items shifted from one factor to another (e.g., items 8, 19 and 22 for the SQU female sample) so as the location of factor. This, in fact, is not surprising and can be explained methodologically. On one hand, EFA has an inherent limitation in which the number of factors can be specified a priori, but the pattern of factor loadings cannot be controlled. Several other studies in which EFA has been employed have yielded a pattern of shifting items (e.g., Abu-Hilal \& Salameh (1992). On the other hand, the shifting items occurred in the smallest sample. Also, while optimism was the first factor and explained greater variance for the female samples, optimism was the second factor for the male sample. This would justify the use of CFA which does not have this kind of limitation; however, a small sample is still a limitation. 
Table 1. Matrix of Factor Loadings, Percent of Explained Variance and Factor Correlations for P. E. Males and Females and Non P. E. Females

\begin{tabular}{|c|c|c|c|c|c|c|}
\hline & \multicolumn{2}{|c|}{ P. E. Males, SQU } & \multicolumn{2}{|c|}{ P.E. Females, SQU } & \multicolumn{2}{|c|}{$\begin{array}{c}\text { Non P. E. Females, } \\
\text { UAEU }\end{array}$} \\
\hline & $\mathrm{I}$ & II & $\mathrm{I}$ & II & I & II \\
\hline Optimism 1 & & .545 & .795 & & .633 & \\
\hline Optimism 2 & & .677 & .847 & & .760 & \\
\hline Optimism 3 & & .711 & .683 & & .687 & \\
\hline Optimism 4 & & .577 & .764 & & .778 & \\
\hline Optimism 5 & & .570 & .414 & $-.432-$ & .768 & \\
\hline Optimism 6 & & .496 & .801 & & .712 & \\
\hline Optimism 7 & & .729 & .487 & & .781 & \\
\hline Optimism 8 & & .373 & & $-.368-$ & .726 & \\
\hline Optimism 9 & & .468 & .848 & & .789 & \\
\hline Optimism 10 & & .593 & .815 & & .855 & \\
\hline Optimism 11 & -.298 & .291 & .417 & $-.291-$ & .740 & \\
\hline Optimism 12 & & .460 & .488 & & .664 & \\
\hline Optimism 13 & & .345 & .291 & & .714 & \\
\hline Optimism 14 & & .382 & .581 & & .787 & \\
\hline Optimism 15 & & .623 & .611 & & .798 & \\
\hline Pessimism 1 & .588 & & & .540 & & .612 \\
\hline Pessimism 2 & .446 & & & .567 & & .610 \\
\hline Pessimism 3 & .628 & & & .582 & & .780 \\
\hline Pessimism 4 & .655 & & $-.586-$ & & & .829 \\
\hline Pessimism 5 & .520 & & & .778 & & .789 \\
\hline Pessimism 6 & .727 & & & .715 & & .859 \\
\hline Pessimism 7 & .691 & & $-.359-$ & & & .806 \\
\hline Pessimism 8 & .652 & & & .673 & & .720 \\
\hline Pessimism 9 & .655 & & & .467 & & .690 \\
\hline Pessimism 10 & .786 & & & .698 & & .692 \\
\hline Pessimism 11 & .707 & & $-.367-$ & .492 & & .840 \\
\hline Pessimism 12 & .533 & & & .717 & & .516 \\
\hline Pessimism 13 & .634 & & $-.326-$ & .524 & & .647 \\
\hline Pessimism 14 & .616 & & & .909 & & .779 \\
\hline Pessimism 15 & .617 & & & .583 & & .857 \\
\hline$\%$ of Variance & 31.61 & 8.13 & 35.80 & 12.67 & 42.92 & 17.05 \\
\hline Factor cor. & & 38 & & & & 29 \\
\hline
\end{tabular}


The first wave of CFA was conducted to test if optimism and pessimism is a onebipolar construct or two distinct constructs. The analysis with one factor specified for the three groups combined revealed a poor fit of model to data. Table 2 shows that model 1 has a poor fit $\left(\chi^{2}=1496.38, \mathrm{df}=104, \mathrm{CFI}=0.606, \mathrm{TLI}=0.545, \mathrm{RMSEA}=0.211\right)$. In comparison, model 2 has a much better fit when two correlated factors were specified $\left(\chi^{2}=238.43\right.$, $\mathrm{df}=$ $103, \mathrm{CFI}=0.962, \mathrm{TLI}=0.955, \mathrm{RMSEA}=0.066)$ indicating that optimism and pessimism are two distinct factors.

The second wave of CFA tested factor-analytic models for the three groups simultaneously. In all of the models, it was specified that one indicator was fixed to 1.0 (reference variable) for the latent factor(s), and the other indicators were estimated. First, we tested a onefactor model for the three groups simultaneously with no constraints -imposing equality across groups or freeing fixed parameters- imposed on the parameters (model 3). The fit was rather poor $\left(\chi^{2}=1610.24, \mathrm{df}=297, \mathrm{CFI}=0.627, \mathrm{TLI}=0.548, \mathrm{RMSEA}=0.122\right)$. In model 4a, all non-target loadings were fixed to zero, and no equality constraints across groups were imposed on any of the parameters and no parameter were freed from default restrictions $\left(\chi^{2}=\right.$ $580.781, \mathrm{df}=309, \mathrm{CFI}=.923, \mathrm{TLI}=.910, \mathrm{RMSEA}=.054)$. However, inspection of some parameters revealed differences across the groups. We inspected the modification indices and freed some residual terms to correlate with other residual terms. For the unconstrained equality model (model 4b), the value of the $\chi^{2}$ statistic was $480.219, \mathrm{df}=291, \mathrm{CFI}=0.946, \mathrm{TLI}=$ $0.933, \mathrm{RMSEA}=0.047$ indicating a better fit than model $4 \mathrm{a}$.

When equality constraints on factor loadings were imposed (model 5), the goodness of fit measures dropped significantly but the indices still reflected a reasonably good fit $(\chi 2=$ $529.717, \mathrm{df}=319, \mathrm{CFI}=.940, \mathrm{TLI}=.932, \mathrm{RMSEA}=.047)$. The CFI, TLI and RMSEA all indicate a reasonable fit of model $4 \mathrm{~b}$ to data. Of particular relevance is the correlation between optimism and pessimism across the groups (see bottom of Table 3). The correlation between the two scales was -.63, -.60, -.46 for P.E male students at SQU, for P.E female students at SQU, for non P.E female students at the UAEU, respectively. When we imposed equality constraints on factor covariances (model 6$)$, the fit indices $(\mathrm{CFI}=.931$, TLI $=.923$ ) dropped further, but the fit was still reasonable. In model 8 we left the constraint of equality of covariances across groups but left constraint on the two P.E. groups. The fit of model 8 was a little better than model 7 indicating that correlation between optimism and pessimism are still invariant across P.E. groups but not invariant across P.E. and non P.E. groups. 
Table 2. Goodness of Fit Indices: Confirmatory Factor-Analytic Model of Optimism and Pessimism for P.E and non P.E. College Students

\begin{tabular}{lccccc}
\hline \multicolumn{1}{c}{ Models } & $\chi^{2}$ & df & CFI & TLI & RMSEA \\
\hline 0. Independence Model & 3877.904 & 360 & & & \\
1. Combined samples one factor & 1496.380 & 104 & .606 & .545 & .211 \\
& & & & & \\
2. Combined samples 2 factors & 238.431 & 103 & .962 & .955 & .066
\end{tabular}

$\underline{\text { Simultaneous analysis }}$

3. On factor, no constraints

1610.240

$297 \quad .627 \quad .548$

.122

4a. Two factors, no constraints

580.78

309

$.923 \quad .910$

.054

4b. 2 factors, no constraints, some residuals left free to correlate

$\begin{array}{lllll}480.219 & 291 & .949 & .933 & .047\end{array}$

5. FL invariant

529.717

$\begin{array}{lll}319 & .940 \quad .932\end{array}$

6. FL V, \& CV invariant

569.062

325

$.931 \quad .923$

.050

7. FL, V, CV \& U invariant

622.993

357

$.924 \quad .924$

.050

8. Same as $7 *$

607.267

356

$.929 \quad 928$

.049

Note: $\mathrm{CFI}=$ comparative fit index, TLI = Tucker-Lewis index, RMSEA = root mean square error of approximation, FL = factor loadings, $\mathrm{CV}=$ factor covariance, $\mathrm{U}=$ measurement residuals. $*$ Factor correlation equal between P.E. males and P.E. females.

The poorest fitted model, model 7, (though statistically not bad) was when equality constraints were imposed on the measurement residuals in addition to equality of factor loadings, variances and covariances $\left(\chi^{2}=622.993, \mathrm{df}=357, \mathrm{CFI}=.924, \mathrm{TLI}=.924, \mathrm{RMSAE}=\right.$ .050). Probably it should be noted that indices of CFI and TLI in the vicinity of .90 and RMSEA les than .10 reflect a reasonable fit. In models $4 \mathrm{~b}, 5,6,7$ and 8 , six of the correlation coefficients among the residuals of observed variables (indicators of optimism: 1 and 2, 2 and 7, 6 and 7, 7 and 8; indicators of pessimism: 6 and 7,7 and 8) were freed to correlate.

Table 3 shows the loading matrix which resulted from the multiple group analysis. The specifications were that all parameters assumed to be equal across groups with six of the correlations among residuals in the observed variables left free (model 7). 
Table 3. Factor Loading Matrix of Optimism and Pessimism for Omani Males and Females and UAE Females

\begin{tabular}{|c|c|c|c|c|c|c|}
\hline & \multicolumn{2}{|c|}{ P. E.Males, SQU ${ }^{\text {a }}$} & \multicolumn{2}{|c|}{ P. E.Females, SQU ${ }^{b}$} & \multicolumn{2}{|c|}{$\begin{array}{c}\text { Non P. E.Females, } \\
\text { UAEU }\end{array}$} \\
\hline & Optimism & Pessimism & Optimism & Pessimism & Optimism & Pessimism \\
\hline opt1 & .695 & 0.00 & .758 & 0.00 & .774 & 0.00 \\
\hline opt2 & .666 & 0.00 & .759 & 0.00 & .797 & 0.00 \\
\hline opt3 & .687 & 0.00 & .886 & 0.00 & .864 & 0.00 \\
\hline opt4 & .891 & 0.00 & .608 & 0.00 & .867 & 0.00 \\
\hline opt5 & .651 & 0.00 & .843 & 0.00 & .886 & 0.00 \\
\hline opt6 & .476 & 0.00 & .697 & 0.00 & .739 & 0.00 \\
\hline opt7 & .445 & 0.00 & .694 & 0.00 & .850 & 0.00 \\
\hline opt8 & .605 & 0.00 & .631 & 0.00 & .793 & 0.00 \\
\hline pes 1 & 0.00 & .730 & 0.00 & .528 & 0.00 & .696 \\
\hline pes 2 & 0.00 & .815 & 0.00 & .732 & 0.00 & .892 \\
\hline pes3 & 0.00 & .854 & 0.00 & .812 & 0.00 & .860 \\
\hline pes 4 & 0.00 & .694 & 0.00 & .856 & 0.00 & .826 \\
\hline pes 5 & 0.00 & .810 & 0.00 & .750 & 0.00 & .773 \\
\hline pes6 & 0.00 & .626 & 0.00 & .663 & 0.00 & .787 \\
\hline pes 7 & 0.00 & .758 & 0.00 & .809 & 0.00 & .776 \\
\hline pes 8 & 0.00 & .707 & 0.00 & .728 & 0.00 & .838 \\
\hline $\begin{array}{l}\text { Factor } \\
\text { Corr. }\end{array}$ & \multicolumn{2}{|c|}{-0.63} & \multicolumn{2}{|c|}{-0.60} & \multicolumn{2}{|c|}{-0.46} \\
\hline
\end{tabular}

Level of optimism and pessimism. MANOVA with group (three groups) as the independent variable and the optimism and pessimism scores as the dependent variables was conducted. MANOVA results showed an overall main effect of group (lambda $=.87, \mathrm{~F}_{(4,596)}=11.090$, p.<.0001). Univariate analyses revealed a main effect of group for optimism $\left(F_{(3,565)}=\right.$ 15.226, p. <.0001); but not for pessimism. 
Table 4. Means, Standard Deviations and F Statistic of differences among the Three Groups

\begin{tabular}{llccc}
\hline Factor & \multicolumn{1}{c}{ Group } & Mean & Std. Deviation & F \\
\hline Optimism & P. E. Male, SQU & 60.004 & $(8.196)$ & \\
& P. E. Female, SQU & 61.306 & $(9.319)$ & $15.226^{*}$ \\
& Female, UAEU & 52.610 & $(13.049)$ & \\
\multirow{2}{*}{ Pessimism } & P. E. Male, SQU & 32.556 & $(10.713)$ & \\
& P. E. Female, SQU & 28.636 & $(10.202)$ & 1.474 \\
& Female, UAEU & 29.880 & $(13.570)$ & \\
\hline${ }^{*} p<.001$ & & & &
\end{tabular}

The multiple comparisons with Scheffe tests $(\mathrm{p} .<.05)$ revealed that P.E male students $(\underline{m}=60.004, \underline{s d}=8.196)$ were significantly more optimistic than non-P.E. female students $(\underline{\mathrm{m}}=52.610, \underline{\mathrm{sd}}=13.049)$. Also P.E. female students $(\underline{\mathrm{m}}=61.306, \underline{\mathrm{sd}}=9.319)$ were significantly more optimistic than non-P.E. female students. As for pessimism, all three groups of students expressed about the same level of pessimism and no group was significantly different from the others. When the average score of optimism $(\underline{\mathrm{m}}=55.26, \underline{\mathrm{sd}}=12.29)$ is compared with that of pessimism ( $\underline{\mathrm{m}}=30.32, \underline{\mathrm{sd}}=12.66)$, it seems that the three groups were significantly more optimistic than pessimistic.

\section{Discussion}

The results of this study support the hypothesis that optimism and pessimism are two distinct but strongly correlated factors and nullify the hypothesis that optimism and pessimism make one bipolar factor. This result supports the results of Marshall et al. (1992) who found that the two constructs were correlated but distinguishable. The responses to the optimism and pessimism scale items demonstrated that the two scales were measured with equal validity and reliability for P.E. and non P.E. college students. Factor loadings bear on the validity issue and uniqueness terms bear on reliability issue. However in light of the CFA results, the indictors were not equally reliable for P.E. and non P.E. students. This result, though, should be interpreted with some caution and should not be confused with the reliability of the instrument in general. Due to small samples and with only females representing the non P.E. individuals, further research that overcomes these limitations may be needed. 
Another relevant result of this study is the correlation between optimism and pessimism. The two constructs were not equally correlated in different samples. Optimism and pessimism were more strongly correlated among P.E. students than among non P.E. students. The non P.E. female students differentiated optimism and pessimism more than the P.E. males and females (Osborne, 2006). This can be interpreted in that optimistic non P.E. students may have a trace of pessimism and those who are pessimistic have a trace of optimism. Optimistic P.E. individuals (males and females) are less likely to be pessimistic and pessimistic are less likely to be optimistic. In fact a P.E. student who is optimistic would be very unpessimistic; and the one who is pessimistic would express very low level of optimism. Again further and more detailed and focused research is needed to confirm these hypotheses. The personal and cognitive characteristics (e.g. anxiety, depression, hopefulness, persistence, etc.) of subjects participating in our samples are not known and one can't make statements beyod the results of the study.

In sum, despite the limitations of the study and reasonable fit of models, it can be concluded at this juncture of research that optimism and pessimism is structured and developed equally across groups. As such one can compare the level of optimism and pessimism across those groups. Without such equality, comparison of level is methodologically not right.

MANOVA results revealed that P.E. individuals were more optimistic than non P.E. individuals. Previous research (Abdel-Khalek \& Lester, 2006) and common sense would support such a result. This result may have a bearing on the dispositional vs. contextual issue. It seems that optimism and pessimism are more likely to be contextual than dispositional. Non P.E. female students live in isolated dormitories five days a week and interact only with the same group of girls in the same dormitory during those days. Girls need permission to move from one hostel to another where movement should be justified. Probably the toll of such environment is high on those girls and may cause them less optimistic. In comparison, girls at the SQU are not similarly restricted since dormitories are in one campus and close to each other. Also, the learning environment is more natural where boys and girls can attend classes together. It should be noted, however that the Omani and the Emirati traditions are similar. Girls are similarly restricted and not allowed to build friendships with boys as the case in the West. 
Boys, on the other hand are freer in terms of movement or interaction. In addition to the fact that they have more freedom to play and exercise, they can do all of that with less restrictions on them than on girls in both Oman and UAE. The difference in conditions of girls in the two countries is that Omani girls are P.E. students and UAE girls are non P.E. students. The difference in level of optimism between the two groups of girls may be attributed to the difference in the major and the life style accompanying this major. Our results provide support to the findings of Abdel-Khalek and Lester (2006). Abdel-Khalek and Lester found that gender was realted to pessimism. Alos, they found that optimisim was related to better outcomes such as good physical health. Therefore, it is not suprising to find that P.E. students are more optimistic than students whith less physical exerices and probably less physical health. Also, Abdel-Khalek (1998) found significant relation between physical health and optimism.

The perplexing result is that the three groups revealed no difference in pessimism. This result may provide support to what Marshall et al. (1992) found; optmimism and pessimism were differentially linked to other variables. In this study, optimism and pessimism were differentially related to gender. However, at this point of research which is at its beginning, no explanation can be provided to explain the differences across gender in optimism but not in pessimism. On the average, however, the three groups were more optimistic than pessimistic. 


\section{References}

Abdel-Khalek, A. M. (1998). Optimism and physical health: A factorial study. Journal of the Social Sciences, 26(2), 45-62.

Abdel-Khalek, A. (2000). A review of research in Arabic for optimism and pessimism. Psychology, 56, 6-27.

Abdel-Khalek, A. \& Lester, D. (2006). Optimism and pessimism and death anxiety: factorial study. Psychological Studies, 8, 361-374.

Abdel-Khalek, A. \& Lester, D. (2006). Optimism and pessimism in Kuwaiti and American college students. International Journal of Social Psychology, 52, 110-126.

Abdel-Khalek, A. \& Maltby, J. (2008). The comparison of predictors of death obsession within two cultures. Death Studies, 32, 366-377.

Abdel-Latif, H. \& Hamadeh, L. (1998). The relationship between optimism/pessimism and the two dimensions of the personality traits: extroversion and neuroticism. Journal of Social Sciences, 26, 83-104.

Abu Hilal, M. (2006) The relationships among optimism, pessimism, depression and anxiety in Emirati female students. (Unpublished data).

Abu-Hilal, M. \& Salameh, K. (1992). Validity and Reliability of the Maslach Burnout Inventory for non-Western teachers. Educational and Psychological Measurement, 52, 161-169. ,

Alansari, B., \& Kazem, A. (2008). Optimism and pessimism in Kuwaiti and Omani undergraduates. Social Behavior and Personality, 36, 503-518.

Carver, C. S.; Scheierb, M. F.; \& Segerstromc, S. C. (2010). Optimism. Clinical Psychology Review, 30, 879-889.

Carver, C \& Connor-Smith, J. (2010). Personality and Coping. Annual Review of Psychology, 61, 679-704. Retrieved on Oct. 25, 2011 from: www.psy.miami.edu/faculty/ccarver/abstracts/10_AnnualReview.pdf

Chang, R., Chang, E., Sanna, L., \& Hatcher, R. (2008). Optimism and pessimism as personality variables linked to adjustment. In Boyle, Matthews, Saklofske (eds.) The SAGE handbook of personality and assessment (Vol. 1: Personality theories and models (pp. 470-485). Thousand Oaks, CA: Sage Publications. 
Gordon, R. (2008). Attributional style and athletic performance: strategic optimism and defensive pessimism. Psychology of Sport and Exercise, 9, 336-350.

Joreskog, K. \& Sorbom, D. (1993). LISREL 8: Structural equation modeling with the SIMPLIS command language. Chicago: Scientific Software International, Inc.

Joreskog, K. G. \& Sorbom, D. (1989). LISREL 7: User's reference guide. Mooresville: Scientific Software, Inc.

Kracher, S. (1995). The elements of the I ching. Shaftesbury, Dorest: Element Book.

Marsh, H. W. (1987). The hierarchical structure of self-concept and the application of hierarchical confirmatory factor analysis. Journal of educational measurement, 24, 17-39.

Marsh, H. W. (1990). A multidimensional, hierarchical model of self-concept: Theoretical and empirical justification. Educational Psychology Review, 2, 77-172.

Marsh, H. W., \& Hocevar, D. (1985). The application of confirmatory factor analysis to the study of self-concept: First and higher order factor structures and their invariance across age groups. Psychological Bulletin, 97, 562-582.

Marshall, G. N.; Wortman, C. B.; Kusulas, J. W.; Hervig, L. K.; Vickers, R. R., (1992). Distinguishing optimism from pessimism: Relations to fundamental dimensions of mood and personality. Journal of Personality and Social Psychology, 62, 1067-1074.

Nicholls, A., Polman, R. Levy, A. \& Backhouse, S. (2008). Mental toughness, optimism, pessimism and coping among athletes. Personality and Individual Differences, 44, 11821192.

Osborne, J. W. (2006). Gender, stereotype threat, and anxiety: psychophysiological and cognitive evidence. Electronic Journal of Research in Educational Psychology, 4, 109138.

Sanders, L. \& Sander, P. (2007). Academic behavioural confidence: A comparison of medical and psychology students. Electronic Journal of Research in Educational Psychology, $5,633-650$.

Scheier, M. F., Carver, C. S., (1985). Optimism, coping, and health: Assessment and implications of generalized outcome expectancies. Health Psychology, 4, 219-247.

Scheier, M. F. \& Carver, C.S. (1992). Effects of optimism on psychological and physical well-being: Theoretical overview and empirical update. Cognitive Therapy and Research, 16, 201-228. 
Shavelson, R. J., Hubner, J., \& Stanton, G. C. (1976). Validation of construct interpretation. Review of Educational Research, 46, 407-441.

Sheier, M. F., Carver, C. S., \& Bridges, M. W. (1994). Distinguishing optimism from neuroticism (and trait anxiety, self-mastery, and self-esteem): a reevaluation of the orientation test. Journal of Personality and Social Psychology, 67, 1063-1070.

Sorbom, D. \& Joreskog, K. (1981). The use of LISREL in sociological model building. in D. J. Jackson \& E. F. Borgatta (Ed.), Factor analysis and measurement in sociological research: A multi-dimensional perspective. Beverly Hills: SAGE Publications Inc. 